\title{
Quasi Two-Day Period Variation of the Geomagnetic Field
}

\author{
Masahiko TAKEDA and Yuji YAMADA* \\ Department of Geophysics, Kyoto University, Kyoto 606, Japan
}

(Received April 14, 1988; Revised December 6, 1988)

\begin{abstract}
A quasi two-day variation is determined from $S d_{\mathrm{I}}$ in the geomagnetic field in the interval from May to August, 1958. Two peaks are found in the power spectrum at 45 and 58 hours in period. The amplitude of the 58 hour period variation increases with geographic latitude and the phase is almost the same at the observatories used in both hemispheres. A calculation of the geomagnetic field variation from winds antisymmetric with the geographic equator reproduces the observed distribution of the amplitude. However, the calculation shows that the phase is the same in both hemispheres except that it is reversed at certain meridians, while the observational results indicate the same phase everywhere.
\end{abstract}

\section{Introduction}

Since MULLER (1972) first found a two-day wave, two-day waves have been observed mainly by meteor radar observation in the upper mesosphere (90-110 km). These waves are observed at various observatories and their characteristics have been revealed (e.g., GlASS et al., 1975; MULLER and NELSON, 1978; CRAIG and ElFORD, 1981; CRAIG et al., 1983; ITO et al., 1984; TSUDA et al., 1988). For instance, these waves have a global scale, travel westward with a longitudinal wavenumber of three and have fairly long vertical wavelengths of approximately 100 $\mathrm{km}$.

If these winds blow in the ionosphere, they should drive the ionospheric dynamo and the resultant ionospheric currents should cause a two-day period geomagnetic variation. However, whether or not the variation exists with certainty is a controversial problem. ITO et al. (1986) simulated the geomagnetic field variation by these winds using a two dimensional ionospheric model and compared the results with the geomagnetic $H$-and $D$-components at Kakioka. These authors concluded that this variation exists and causes a movement of the $S q$ focus. On the other hand, PARKINSON (1982) examined the variation of the geomagnetic $D$ component and found no geomagnetic effect corresponding to the two-day variation winds. In this paper, we first examine a geomagnetic field variation with about a two day period at several observatories at low latitudes. Next we simulate the geomagnetic field variation from a two-day wave in the wind using the method

*Now at Hiroshima District Meteorological Observatory, Hiroshima 730, Japan. 
presented by TAKEDA (1982) and compare the results of the calculation with those from the data analysis.

\section{Analysis of the Geomagnetic Field}

There are several methods available to analyze the day-to-day variation of the geomagnetic field. If we calculate an instantaneous equivalent current system using the geomagnetic hourly values from observatories distributed all over the world, such as those used in TAKEDA and ARAKI (1984) for analysis of the geomagnetic $S q$ field, we can find the variation of the shape of the equivalent current system with a time resolution of an hour. However, this method needs computer-readable data from many observatories nearly evenly distributed in the world. On the other hand, if we use the geomagnetic field variation at one observatory, the data acquisition is easy; however, the time resolution in the amplitude of the diurnal variation becomes one day. Removal of the disturbance field also should be considered. In this study we estimate the geomagnetic field variation caused by ionospheric currents with data from two observatories by the method of KANE (1973). He regarded the variation as being produced purely by ionospheric currents, and called the variation $S d_{\mathrm{I}}$. Using the geomagnetic $H$-component of two observatories at different latitudes in the same meridian, $S d_{\mathrm{I}}$ is calculated by the following equation:

$$
S d_{\mathrm{I}}=H\left(\theta_{2}\right)-\left(H\left(\theta_{1}\right)-S q\left(\theta_{1}\right)\right) \cos \theta_{2} \sec \theta_{1},
$$

where $\theta_{1}$ and $\theta_{2}$ are the geomagnetic latitudes of the higher and lower latitude observatories, respectively, and where $S q$ is the $H$-component of the mean geomagnetic $S q$ field. At the lower latitude observatory (at $\theta_{2}$ ) geomagnetic disturbance fields from the currents outside of the ionosphere are deduced by reference to observations (at $\theta_{1}$ ) near the $S q$ focus at the same longitude. That is, the disturbance field is assumed $D s t$-like in the meridian and the observed geomagnetic field at the lower latitude observatory is corrected by the inferred disturbance field. As a result, the geomagnetic field variation by the ionospheric currents is obtained as $S d_{\mathrm{I}}$. In this sense, $S d_{\mathrm{I}}$ can be regarded as an extension of the $S q$ field to the disturbed period. In fact, KANE (1978) found that an $S q(H)$-like pattern at the low latitude station exists in $S d_{\mathrm{I}}$ even in disturbed periods. Taking this into consideration, we have calculated the $S d_{\mathrm{I}}$ at observatories at low latitudes and examined its day-to-day variation.

We have used data from ten pairs of observatories at low latitudes, as shown in Fig. 1. Of these pairs, seven are to the north and three to the south of the geomagnetic equator. Circles represent observatories at which $S d_{\mathrm{I}}$ is obtained, and triangles the reference observatories which are situated at higher latitudes (near the location of the $S q$ focus) in almost the same meridians. The dot-dashed line represents the geomagnetic equator. We have analyzed the IGY data, because a relatively dense distribution of observatories enables us to study the global structure of the geomagnetic field variation at low latitudes. In this paper we discuss the approximately two day period variation in the time interval from May to August 


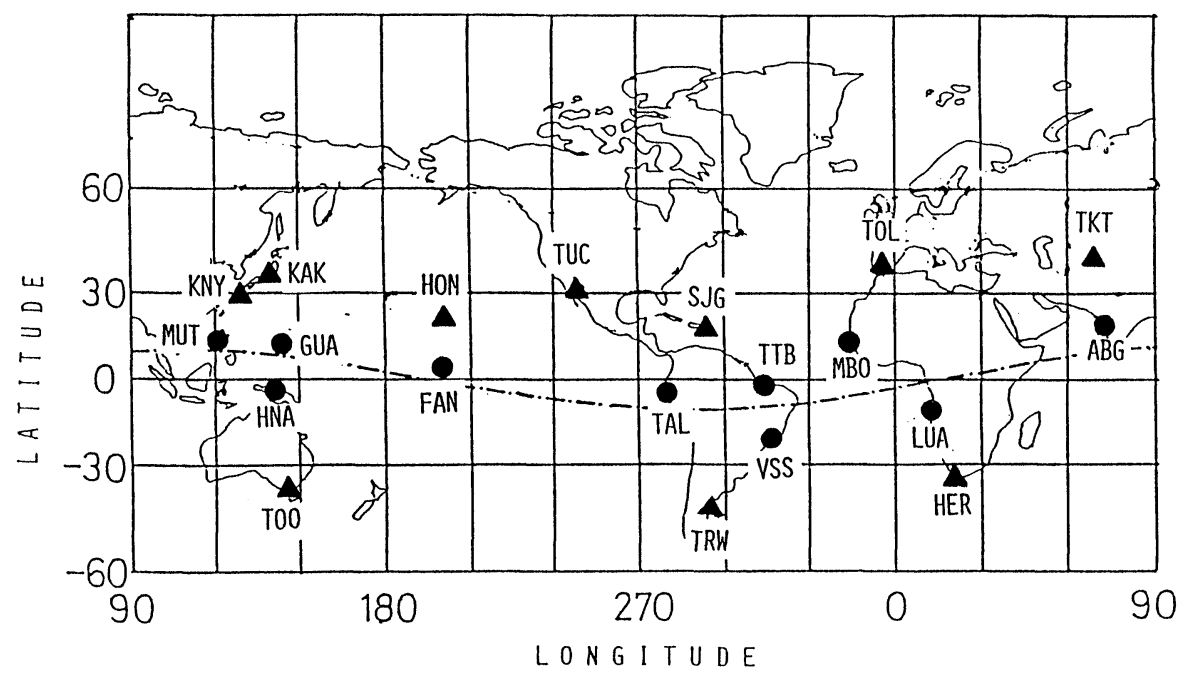

Fig. 1. Distribution of observatories where $S d_{1}$ was obtained (circles) and the reference observatories (triangles) and their abbreviated names. Dot-dashed line represents the geomagnetic equator.

1958, when the variation appears most clearly.

Figure 2 shows the variation of the daily amplitude of $S d_{\mathrm{I}}$ at Guam (GUA), Alibag (ABG), Fanning (FAN) and Hollandia (HNA) during the period from May to August 1958. A clear regional difference is found in the amplitude of variations with periods of less than five days. The amplitude of the variations is largest at Alibag and smallest at Fanning. In order to clarify this regional difference in the short period fluctuation, FFT is applied to the raw hourly values of the $S d_{\mathrm{I}}$ and not to the daily amplitude of $S d_{\mathrm{I}}$, because if we take the amplitude, the Nyquist frequency becomes $1 / 2 \mathrm{day}^{-1}$ and therefore it is difficult to find out the variation with a nearly two day period.

Figure 3 shows the power spectrum for Alibag (ABG) (top two panels), M'bour (MBO) (middle left panel) and Fanning (FAN) (middle right panel). The bottom panels give the phase differences between Alibag and M'bour (left) and between Alibag and Fanning (right). The abscissas represent the period from 36 to 72 hours. There are two peaks at 45 and 58 hours in the spectrum for Alibag. For M'bour no clear peak is seen at 45 hours, but the peak at 58 hours is more pronounced than that for Alibag. The phase difference at 58 hours is less than $30 \mathrm{deg}$. in both pairs of observatories.

Figure 4 presents the power spectrum at Guam (GUA) and Hollandia (HNA) in the left panels and at Tatuoca (TTB) and Vassouras (VSS) on the right. These two pairs of observatories are situated in the same longitudes but to the north and south of the geomagnetic equator, respectively. There are peaks at about 58 hours at Guam, Hollandia and Vassouras, while there is no clear peak at Tatuoca. On the 

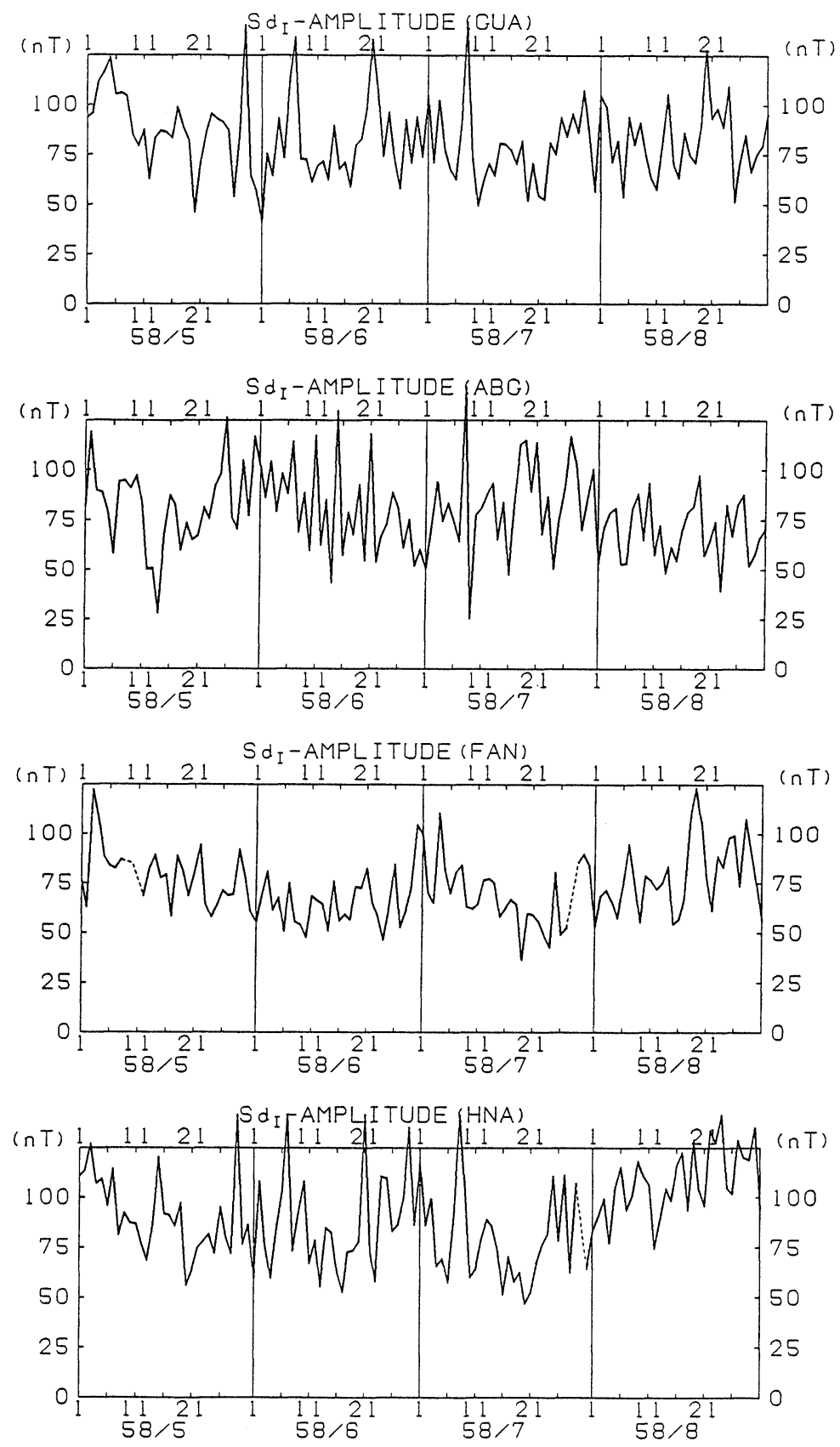

Fig. 2. The variation of the daily amplitude of $S d_{\mathrm{I}}$ at Guam (top), Alibag (second), Fanning (third) and Hollandia (fourth) from May to August 1958. 

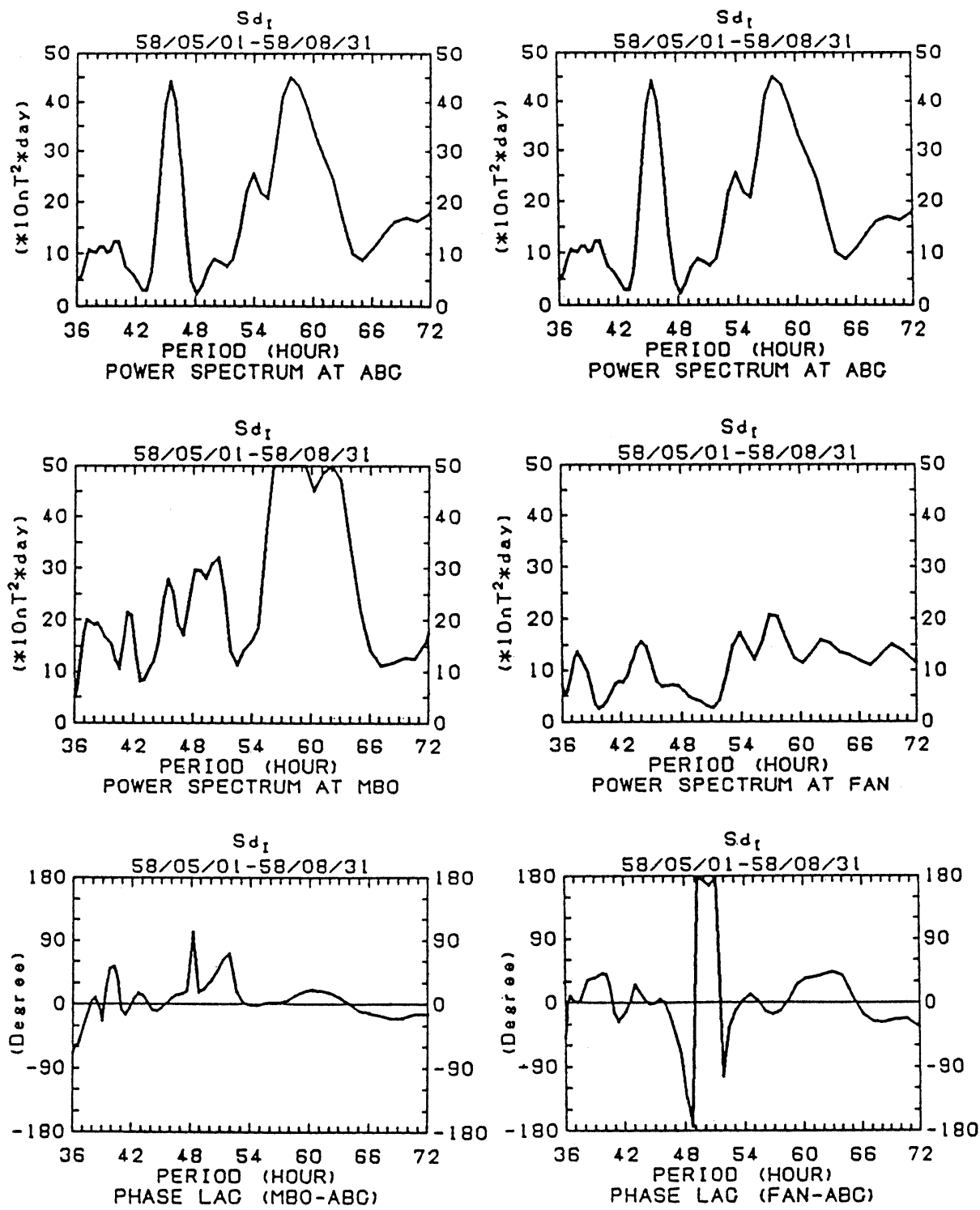

Fig. 3. The power spectrum at Alibag (top two panels), M'bour (middle left panel) and Fanning (middle right panel) from May to August, 1958. The bottom panels give the phase difference between Alibag and M'bour (left) and between Alibag and Fanning (right). The abscissas represent the period from 36 to 72 hours. 

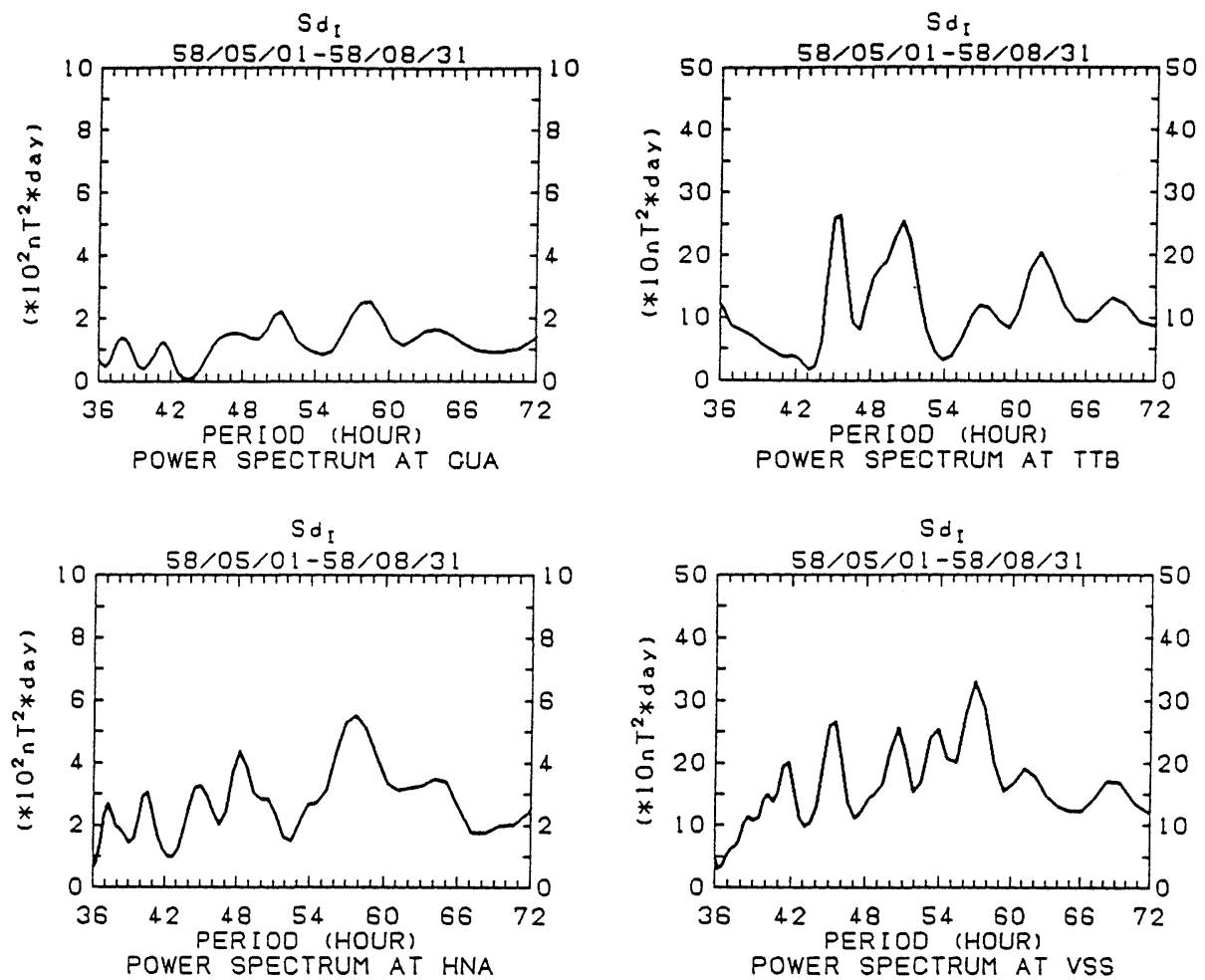

$S d_{I}$
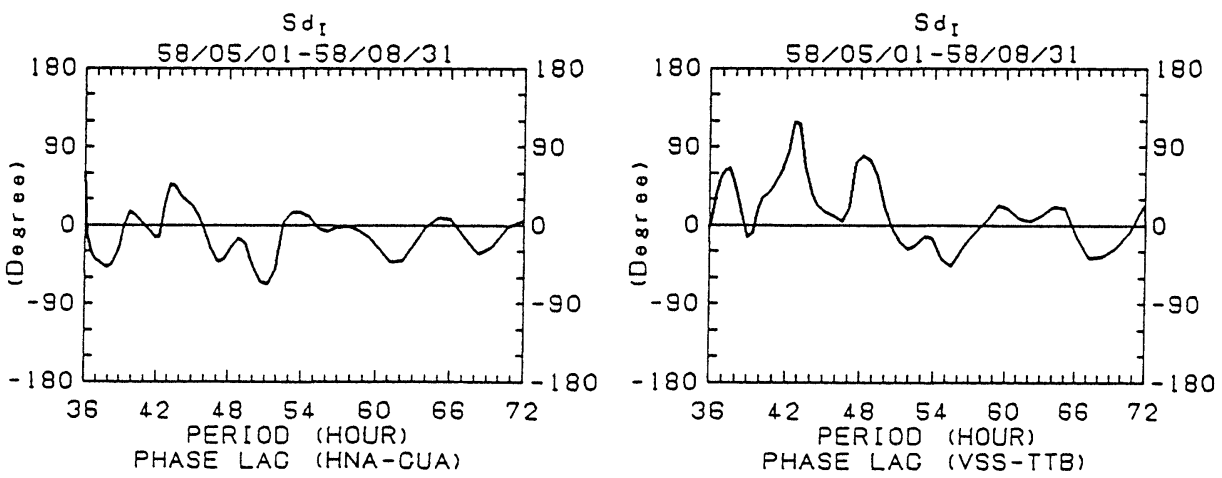

Fig. 4. Same as in Fig. 3 but at Guam and Hollandia (left) and at Tatuoca and Vassouras (right). These two pairs of observatories are situated in the same meridian but to the north and south of the geomagnetic equator, respectively. 
other hand, there is also a peak at about 45 hours at Guam, Tatuoca and Vassouras, while the corresponding peak at Hollandia is less pronounced. The phase difference in the paired observatories is nearly zero at the 58 hour period. This means that the variation with the 58 hour period is in-phase in the two hemispheres. Since the peaks appear in the spectrum at plural observatories, these peaks, especially at 58 hour, are unlikely to be spurious.

Figure 5 shows the power at the 58 hour period at each observatory. The abscissa represents the absolute value of geomagnetic latitude. Open and closed circles represent the observatories to the north and south of the geomagnetic equator, respectively. It can be seen that a positive correlation exists between the geomagnetic latitude and the power if we ignore one anomalous observatory which is situated in the upper left corner. This anomalous point may be caused by the poor quality of the original geomagnetic data, but if this is real, it is possible that this is caused by a local enhancement of the wind. If the steady two-day wave found by the meteor radar observation generates this geomagnetic field variation, these features should be consistent with those of the geomagnetic field variation calculated by the dynamo theory using the winds. ITO et al. (1986) simulated the ionospheric currents by this wave on the assumption of a thin shell ionosphere and completely antisymmetric winds. They showed that the $H$-component was anti-symmetric with the equator. This is inconsistent with the result of our analysis, shown in Fig. 4.

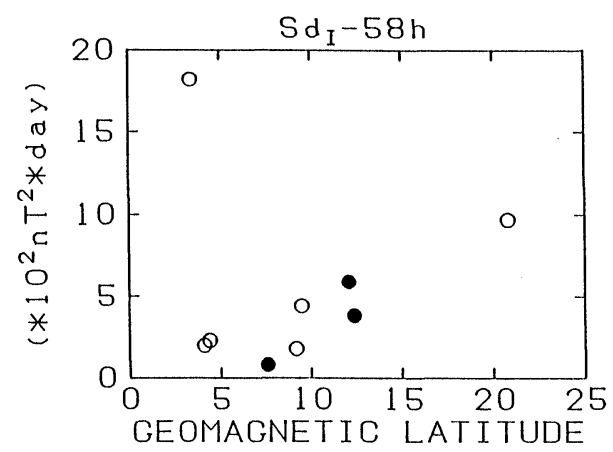

Fig. 5. The peak power at the 58 hour period at each observatory. The abscissa represents the absolute value of geomagnetic latitude. Open and closed circles represent the observatories to the north and south of the geomagnetic equator, respectively.

\section{Simulation of the Quasi Two-Day Variation}

To examine the geomagnetic field variation from the two-day wind we have simulated the geomagnetic field variation produced by this wind. In this study we have calculated three-dimensional ionospheric currents and field-aligned currents generated by the ionospheric dynamo by the method of TAKEDA (1982), taking the 
difference between geographic and geomagnetic coordinates into consideration. The effects of the field-aligned currents which tend to equalize the electrostatic potential between the conjugate points are considered. The wind model used here is based on the observation by ITO et al. (1984) and is the same as that used in ITO et al. (1986), except that these authors did not make a distinction between geographic and geomagnetic coordinates. The maximum wind velocity is $20 \mathrm{~m} / \mathrm{s}$ at $90 \mathrm{~km}$ altitude at $30^{\circ}$ latitude and the wind blows only below $105 \mathrm{~km}$. The latitudinal structure is anti-symmetric with the geographic equator (e.g., TSUDA et al., 1988), and the longitudinal wavenumber is three (e.g., MUller and NELSON, 1978; CrAig et al., 1983). The conductivity model which we used is the same as in TAKEDA and MAEDA (1980).

Figure 6 shows the geomagnetic variation obtained at noon at $00 \mathrm{~h}$ UT (top) and $06 \mathrm{~h}$ UT (bottom). The ordinates give the amplitude and the abscissas geomagnetic latitude. Thick, dotted and thin lines represent the $H$-, $D$ - and $Z$ components, respectively. The effects of both the ionospheric currents and field aligned currents are taken into consideration. It is seen that at both universal times the $H$-component is unchanged in sign around the equator and has the same sign, at least in the region from $-25^{\circ}$ to $25^{\circ}$ in latitude. This means that the geomagnetic field variation produced by this wind is in-phase throughout this region, consistent with the results of our analysis of observational data. As for the amplitude at $00 \mathrm{~h}$ $\mathrm{UT}$, it has a maximum near the equator and decreases with latitude in the region

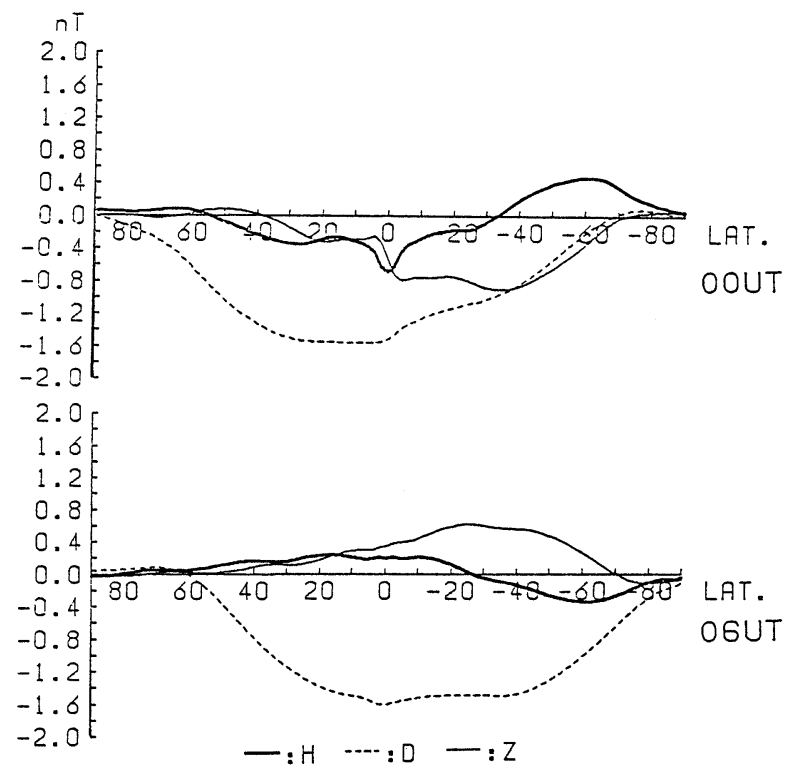

Fig. 6. Calculated geomagnetic variation at noon at $00 \mathrm{~h} \mathrm{UT} \mathrm{(top)} \mathrm{and} 06 \mathrm{~h}$ UT (bottom) caused by both ionospheric and field-aligned currents. Thick, dotted and thin lines represent $H$-, $D$ - and Z-components, respectively. 
from the equator to plus or minus $15^{\circ}$ in latitude in both hemispheres, and at $06 \mathrm{~h}$ UT it is almost constant with latitude. Although this amplitude distribution is not fully consistent with our result for the $H$-component, it is likely that the geomagnetic field variation with about a two-day period found by the present analysis is caused by this two-day wind.

Figure 7 gives the equivalent current system caused by the two-day wave at $00 \mathrm{~h}$ UT. This is obtained by the least squares fitting of the calculated geomagnetic field variation. It is seen that there are six current vortices whose centers are located near the equator. This results from the assumed wavenumber (three) of the model wind. The intensity of the current vortex is $4 \mathrm{kA}$, which is $2-4 \%$ of the $S q$ currents. Currents in the low latitude region flow mainly in the north-south direction, but the east-west component of the currents is not necessarily reversed at the equator. This means that the geomagnetic $H$-component produced by the winds is not necessarily reversed at the equator. This is consistent with the results of our analysis. However, while our simulation predicts that in the region where the longitude is different by $60^{\circ}$ or $180^{\circ}$ the phase is reversed, the phase in our analysis is almost the same in different longitudinal regions. This may result from the selection of the observatories in our analysis, but suggests the possibility that winds of other structure should also be considered as a source of the two-day variation. For example, it is possible that the longitudinal wavenumber of the winds is not three, but is nearly equal to zero. This should be examined in more detail.

The dominance of the north-south component in the currents at low latitudes suggests that the two-day variation should appear more clearly in the $D$-component.

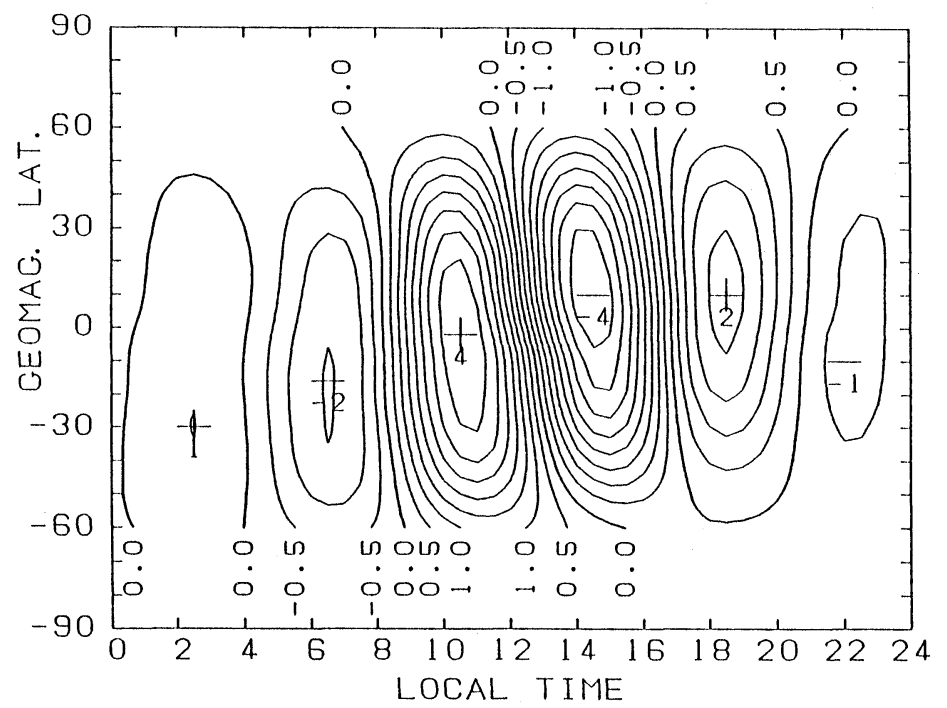

Fig. 7. Equivalent current system for the two-day wave at $00 \mathrm{~h}$ UT. The ordinate represents geomagnetic latitude, and the abscissas represent local time. Contours are drawn at every $0.5 \mathrm{kA}$. 
However, it is difficult to remove the effect of disturbance fields, especially those caused by the currents outside of the ionosphere from the geomagnetic $D$ component variations. A contamination from such disturbance fields may be the cause for PARKINSON (1982) not having detected the quasi-two day period variation in the $D$-component. However, if we succeed in excluding the disturbance field from the $D$-component variation, it is expected that variation by the two-day waves would result. In order to clarify the geomagnetic field variation associated with the two-day wave in wind, it is necessary to examine the geomagnetic field variations, including the $D$-component, at many observatories with simultaneous observations of the wind.

The authors wish to thank Prof. M. Sugiura for valuable discussions. The geomagnetic data used in the present study were obtained through the World Data Center C2 for Geomagnetism, and the data processing was performed using facilities at the Data Processing Center, both at Kyoto University.

\section{REFERENCES}

Craig, R. L. and W. G. Elford, Observations of the quasi 2-day wave near $90 \mathrm{~km}$ altitude at Adelaide, J. Atmos. Terr. Phys., 43, 1051-1056, 1981.

Craig, R. L., R. A. Vincent, S. P. Kingsley, and H. G. Muller, Simultaneous observations of the quasi 2-day wave in the northern and southern hemispheres, J. Atmos. Terr. Phys., 45, 539-541, 1983.

Glass, M., J. L. Fellous, M. Masseheuf, A. Spizzichino, I. A. Lysenko, and Yu. I. Portniaghin, Comparison and interpretation of the results of simultaneous wind measurements in the lower thermosphere at Garchy (France) and Obninsk (U.S.S.R.) by meteor radar technique, J. Atmos. Terr. Phys., 37, 1077-1087, 1975.

Ito, R., T. Tsuda, T. Aso, and S. Kato, Long period oscillations in the meteor winds observed over Kyoto during 1978-1983, J. Geomag. Geoelectr., 36, 173-188, 1984.

Ito, R., S. Kato, and T. Tsuda, Consideration of an ionospheric wind dynamo driven by a planetary wave with a two-day period, J. Atmos. Terr. Phys., 48, 1-13, 1986.

Kane, R. P., An estimation of the equatorial electrojet strength, J. Atmos. Terr. Phys., 35, 1565-1567, 1973.

Kane, R. P., $S q$ variation at low latitudes during geomagnetic storms, J. Geophys. Res., 83, 5312-5315, 1978.

Muller, H. G., Long period meteor wind oscillation, Phil. Trans. R. Soc., A271, 585-591, 1972.

Muller, H. G. and L. Nelson, A traveling quasi 2-day wave in the meteor region, J. Atmos. Terr. Phys., 40, 761-766, 1978.

Parkinson, W. D., Bi-diurnal geomagnetic variation, Ann. Geophys., 38, 327-329, 1982.

TAKedA, M., Three-dimensional ionospheric currents and field aligned currents generated by asymmetrical dynamo action in the ionosphere, J. Atmos. Terr. Phys., 44, 187-193, 1982.

Takeda, M. and T. Araki, Time variation of instantaneous equivalent $S q$ current system, J. Atmos. Terr. Phys., 46, 911-915, 1984.

TAKedA, M. and H. MAEDA, Three dimensional structure of ionospheric currents, 1. Currents caused by diurnal tidal winds, J. Geophys. Res., 85, 6895-6899, 1980.

TsudA, T., S. Kato, and R. A. Vincent, Long period wind oscillations observed by the Kyoto meteor radar and comparison of the quasi-2-day wave with Adelade HF radar observations, J. Atmos. Terr. Phys., 50, 225-230, 1988. 